\title{
Enhanced gas barrier properties of graphene oxide/rubber composites with strong interfaces constructed by graphene oxide and sulfur
}

\author{
Long Zheng \\ Beijing University of Chemical Technology \\ Stephen Jerrams \\ Technological University Dublin, stephen.jerrams@tudublin.ie \\ Zongchao Xu \\ Beijing University of Chemical Technology
}

See next page for additional authors

Follow this and additional works at: https://arrow.tudublin.ie/cerart

Part of the Polymer and Organic Materials Commons

\section{Recommended Citation}

Long Zheng, Stephen Jerrams, Zongchao Xu, Liqun Zhang, Li Liu, Shipeng Wen, Enhanced gas barrier properties of graphene oxide/rubber composites with strong interfaces constructed by graphene oxide and sulfur, Chemical Engineering Journal, Volume 383, 2020, 123100, ISSN 1385-8947, DOI: 10.1016/ j.cej.2019.123100.

This Article is brought to you for free and open access by the Centre for Elastomer Research at ARROW@TU Dublin. It has been accepted for inclusion in Articles by an authorized administrator of ARROW@TU Dublin. For more information, please contact arrow.admin@tudublin.ie, aisling.coyne@tudublin.ie,gerard.connolly@tudublin.ie. Funder: National Basic Research Program of China; National Natural Science Foundation of China; National Key R\&D Program of China

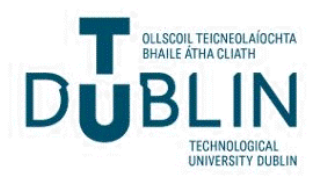




\section{Authors}

Long Zheng, Stephen Jerrams, Zongchao Xu, Liqun Zhang, Li Liu, and Shipeng Wen

This article is available at ARROW@TU Dublin: https://arrow.tudublin.ie/cerart/23 


\title{
Enhanced gas barrier properties of graphene oxide/rubber composites with strong interfaces constructed by graphene oxide and sulfur
}

\author{
Long Zheng ${ }^{\mathrm{a}, \mathrm{b}}$, Stephen Jerrams ${ }^{\mathrm{c}}$, Zongchao Xu ${ }^{\mathrm{a}, \mathrm{b}}$, Liqun Zhang ${ }^{\mathrm{a}, \mathrm{b}}$, Li Liu ${ }^{\mathrm{a}, \mathrm{b}, *}$, Shipeng Wen ${ }^{\mathrm{a}, \mathrm{b}, *}$ \\ a State Key Laboratory of Chemical Resource Engineering, Beijing University of Chemical Technology, Beijing 100029, China \\ ${ }^{\mathrm{b}}$ Beijing Engineering Research Center of Advanced Elastomers, Beijing University of Chemical Technology, Beijing 100029, China \\ ${ }^{\mathrm{c}}$ Centre for Elastomer Research, Technological University Dublin, Dublin, Ireland
}

\section{H I G H L I G H T S}

- S-GO hybrids were prepared by in situ growth of sulfur on the surface of GO sheets.

- S-GO hybrids crosslinked SBR molecules and dispersed uniformly in SBR matrix.

- Strong chemical interfaces were constructed between S-GO and SBR molecules.

- S-GO/SBR composites exhibit unique gas barrier properties and mechanical strength.

\section{A R T I C L E I N F O}

\section{Keywords:}

Graphene oxide

Hybrids

Rubber composites

Barrier properties

\section{G R A P H I C A L A B S T R A C T}

(a)

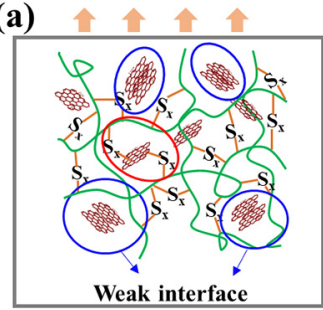

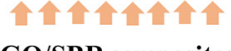

GO/SBR composites
Weak interface

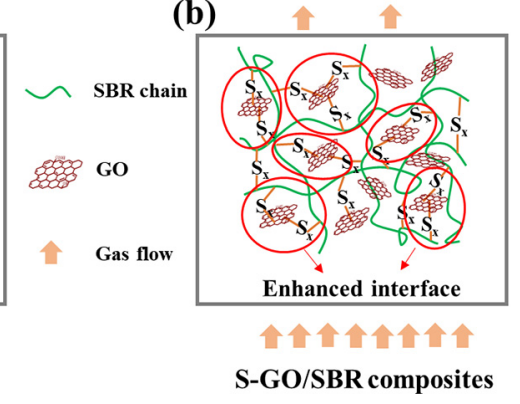

\begin{abstract}
A B S T R A C T
Constructing strong interfacial interactions and complex filler networks is crucial to establishing high gas barrier properties in rubber composites. In this research, sulfur-graphene oxide (S-GO) hybrids were prepared by in situ growth of sulfur on the surfaces of GO sheets. The S-GO hybrids were also introduced into butadiene styrene rubber (SBR) using a green method of latex compounding. Results showed that sulfur could melt and spread on the surface of the GO during the crosslinking process at high temperatures. This process prevented the aggregation of GO and resulted in a fine dispersion of GO and complex filler networks in S-GO/SBR composites. More importantly, the sulfur particles on the GO surface not only aided the crosslinking of rubber molecules, but also chemically reacted with the GO radicals generated at high temperatures. This occurred by the homolytic cleavage of oxygen-containing groups, which thereby constructed covalent interfaces between the GO and SBR molecules. Due to these strong interfaces and complex filler networks, the tensile and tear strength of S-GO/SBR composites increased by $66.2 \%$ and $26.6 \%$, respectively, when compared with conventional GO/SBR composites. The gas permeability coefficient of S-GO/SBR composites was decreased dramatically by $50.7 \%$ and $23.3 \%$ by comparison with that of pure SBR and GO/SBR composites, respectively. The apparent improvement demonstrated that the facile and effective method used in this research may open up new opportunities for the development of multifunctional rubber crosslinking agent as well as the fabrication of rubber composites with high performance.
\end{abstract}

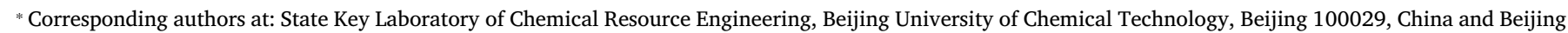
Engineering Research Center of Advanced Elastomer, Beijing University of Chemical Technology, Beijing 100029, China.

E-mail addresses: liul@mail.buct.edu.cn (L. Liu), wensp@mail.buct.edu.cn (S. Wen). 


\section{Introduction}

Rubber composites with high gas barrier properties are widely used in aerospace, tire inner liners, chemical protective equipment and sealing applications due to their high elasticity and heightened ability to recover after compression [1]. However, raw rubbers are highly permeable to most gases, since large free volumes exist among the rubber molecules when the materials are used above the glass transition temperature. Although the introduction of crosslink bonds can shorten the distances between rubber molecules, there are still numerous free volumes in rubber matrices, resulting in ready penetration by small gas molecules.

In order to efficiently improve gas barrier properties, a certain amount of nanoparticles are routinely filled into rubbers to form filler networks, creating tortuous paths inhibiting gas molecules penetrating the rubber matrices. More importantly, the strong interfaces between nanoparticles and rubber molecules are necessary to restrict chain mobility and further reduce free volumes between nanoparticles and rubber molecules. Among a range of particles, the lamellar particles, such as clay [2,3], layered double hydroxides (LDH) [4,5] and graphene (GE) or graphene oxide (GO) [6-8], are more advantageous in enhancing the gas barrier properties of rubber composites due to their higher aspect ratios when compared with spherical and fibrous particles [9]. In particular, GE or GO has a large surface area and virtually a monolayer structure, making it widely used in many fields [10-12]. More importantly, abundant oxygen-containing groups present on the surface of GO, such as the epoxide, hydroxyl and carboxyl groups, and could form strong interactions with polar rubber molecules via hydrogen bonds or ionic bonds [13-15]. Therefore, GO is a good candidate to be used in rubber composites with high gas barrier properties.

However, GO has limited compatibility with some non-polar rubbers (e.g. natural rubber (NR), butadiene styrene rubber (SBR)) due to its hydrophilic nature $[16,17]$, resulting in weak interfaces between them. Therefore, surface modifications of GO were required to tailor the interfaces in rubber composites. For example, Yang et al. [18] modified GO with octadecylamine (ODA) and prepared GO-ODA/brominated butyl rubber (BIIR) composites by solution mixing. The results showed that GO-ODA/BIIR nanocomposites had superior gas barrier properties to BIIR, benefitting from the strong interaction between GO-ODA and BIIR. Huang et al. [19] grafted bis(triethoxysilylpropyl)tetrasulfide (BTESPT) on the surface of GO to obtain functionalized GO (SGO), then SGO was incorporated into NR to prepare SGO/NR composites. The results showed a $48 \%$ reduction in the air permeability was achieved when compared with pure NR. This was attributed to the molecularlevel dispersion of SGO and strong covalent interfaces between SGO and NR chains formed via the bridge effect of sulfur in BTESPT.

Sulfur is the most widely used crosslinking agent in rubber industry. After crosslinking reaction between sulfur and rubber molecules at high temperature, three-dimensional crosslinking network could be formed in rubber composites. Lavorgna et al. [6] and Kaciulis et al. [20] found reduced graphene oxide (rGO) interfered with the pathways of crosslinking reaction in sulfur crosslinked NR composites, thus resulting the strong interfacial interactions between rGO and NR molecules. In our previous research, GO was modified with tea polyphenol (TP) and further compounded with SBR. It was found that the TP reacted with the sulfur during crosslinking at high temperature. The sulfur served as a bridge to link GO and rubber chains, resulting in strong interfacial interactions and high performance [21]. However, it should be pointed out that only a few of GO sheets had the opportunity to contact with sulfur particles in the $\mathrm{GO} /$ rubber composites prepared by physically mixing sulfur with GO/SBR compound, leading to the low degree of connection between GO and SBR molecules. To further understand the contribution sulfur makes to the GO-rubber molecules interfaces and improve the gas barrier properties of $\mathrm{GO} /$ rubber composites, sulfur particles generated by the reaction of thiosulfate and acid were in situ deposited on the surface of GO to form sulfur-GO (S-GO) hybrids. Then, the resultant S-GO hybrids were filled into SBR by latex compounding to obtain S-GO/SBR composites. The S-GO structure, dispersion of the S-GO, the filler network and crosslinking density of the composites were characterized. Most importantly, the interfacial interactions between SGO and SBR molecules and their contribution toward gas barrier properties of composites were primarily investigated. Owing to the complex filler networks and the strong interfaces, the pathways and diffusion times of nitrogen molecules in the SBR matrices were greatly prolonged. The gas permeability coefficients of S-GO/SBR composites were decreased by $50.7 \%$ and $23.3 \%$ when compared with those of pure SBR and GO/SBR composites, respectively.

\section{Materials and methods}

\subsection{Materials}

GO was prepared by a modified Hummers method [22]. SBR latex with a styrene content of $23 \%$ was obtained from Jilin Petrochemical Co., Ltd (China). Sodium thiosulfate $\left(\mathrm{Na}_{2} \mathrm{~S}_{2} \mathrm{O}_{3} \cdot 5 \mathrm{H}_{2} \mathrm{O}\right.$, AR) was purchased from Aladdin. Hydrochloric acid ( $\mathrm{HCl}, 35-38 \%)$ and Calcium chloride $\left(\mathrm{CaCl}_{2}, \mathrm{AR}\right)$ were purchased from the Beijing Chemical Factory (China). Zinc oxide (ZnO), stearic acid (SA), 1,4-Benzenediamine, N-(1methylethyl)-N'-phenyl (antioxidant, 4010NA), and N-Cyclohexyl-2benzothiazolesulfenamide (accelerant, CZ) were all commercially available.

\subsection{Preparation of S-GO hybrids, GO/SBR and S-GO/SBR composites}

The preparation processes of S-GO hybrids, GO/SBR and S-GO/SBR composites are shown in Fig. 1. Firstly, GO was fully exfoliated in deionized water (DW) under sonication for $30 \mathrm{~min}$ to obtain a GO suspension $(3 \mathrm{mg} / \mathrm{ml}) . \mathrm{Na}_{2} \mathrm{~S}_{2} \mathrm{O}_{3}$ aqueous solution $(0.625 \mathrm{mmol} / \mathrm{ml}$, $59.6 \mathrm{ml}$ ) was added slowly to the $\mathrm{GO}$ suspension $(500 \mathrm{ml})$ and stirred for $30 \mathrm{~min}$ to obtain a homogenous suspension. Afterwards, $\mathrm{HCl}$ aqueous solution $(2.74 \mathrm{mmol} / \mathrm{ml}, 43.8 \mathrm{ml})$ was added dropwise at a rate of $10 \mathrm{ml} / \mathrm{min}$ to the mixture and stirred for $2 \mathrm{~h}$ at room temperature. During this process, the GO provided nucleation points and sulfur in situ grew on the surface of GO nanosheets. The reaction equation for the sulfur formation is shown in Eq. (1). It is noted that the by-products $\mathrm{NaCl}$ existed in the water in the form of $\mathrm{Na}^{+}$and $\mathrm{Cl}^{-}$, and $\mathrm{SO}_{2}$ dissolved in the water to form sulfurous acid. They were moved away after the mixture was repeatedly centrifuged and washed with DW until the supernatant was neutral. Therefore, these by-products would not affect the hybrid and/or the following composite formation. Finally, the settled product was collected and freeze dried for $72 \mathrm{~h}$ to obtain a S-GO hybrids powder. The content of sulfur in S-GO hybrids was $39.92 \%$, which was measured by vario EL cube elemental analysis instrument (Elementar Analysensysteme $\mathrm{GmbH}$ ). Also, a reference sulfur sample without GO was synthesized by the same method.

$\mathrm{Na}_{2} \mathrm{~S}_{2} \mathrm{O}_{3}+2 \mathrm{HCl} \rightarrow 2 \mathrm{NaCl}+\mathrm{S}+\mathrm{H}_{2} \mathrm{O}+\mathrm{SO}_{2}$

Thereafter, the S-GO hybrids powder were directly dispersed in DW $(3 \mathrm{mg} / \mathrm{ml}$ ) and sonication for $30 \mathrm{~min}$ before adding to SBR latex with vigorous stirring. Then the mixture was co-coagulated using flocculant $\mathrm{CaCl}_{2}$ solution ( $1 \mathrm{wt} \%$ ) to provide the S-GO/SBR masterbatches. The concentration of GO and sulfur in the masterbatches were 3 and $2 \mathrm{phr}$ (parts per hundreds of rubber), respectively. The S-GO/SBR masterbatches obtained were washed three times with DW to remove the $\mathrm{CaCl}_{2}$. After washing three times, no chloride ion was detected in the DW. Then the masterbatches were dried at $60^{\circ} \mathrm{C}$ in a vacuum oven for $12 \mathrm{~h}$. Subsequently, the S-GO/SBR masterbatches were mixed with other rubber ingredients in a two-roll mill. The ingredients and their concentration complied with the formula: $\mathrm{ZnO} 5 \mathrm{phr}$; SA 1 phr; 4010NA 2 phr; CZ 2 phr.

For comparison, GO/SBR masterbatches without sulfur were also prepared by the same method. The GO content in the GO/SBR 


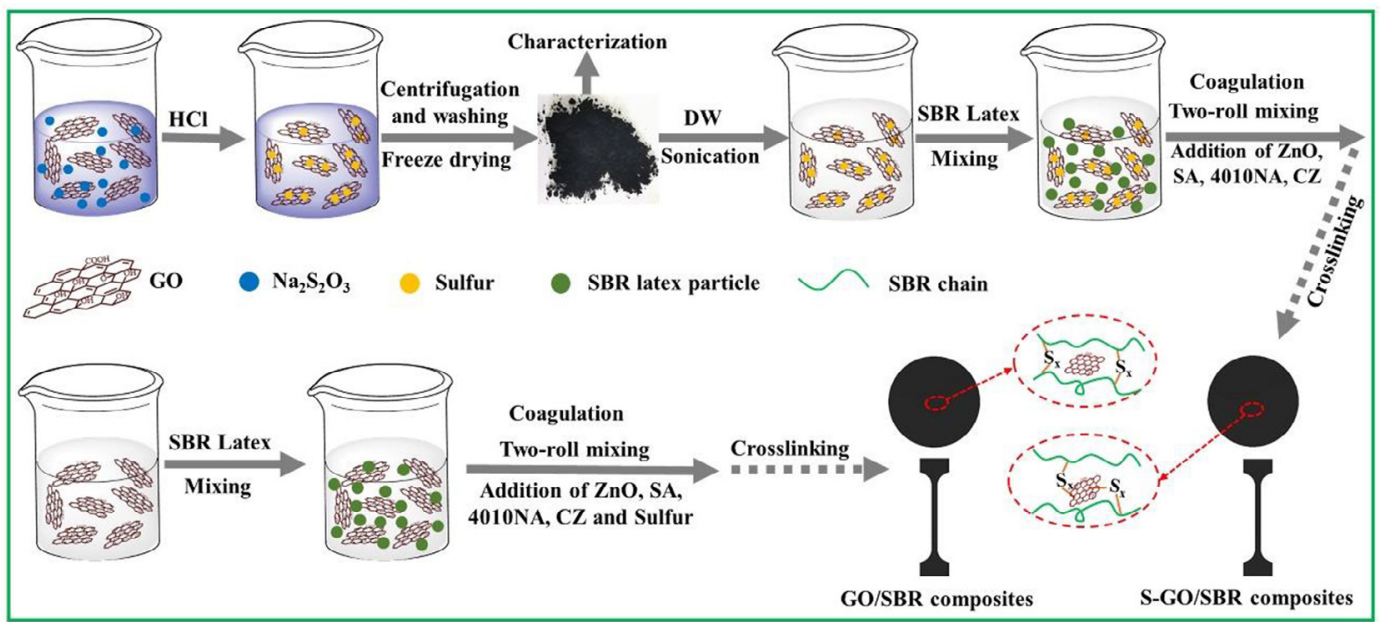

Fig. 1. Schematic of the preparation of S-GO hybrids, S-GO/SBR and GO/SBR composites.

masterbatches was 3 phr. Afterwards, the GO/SBR and pure SBR compounds were prepared by mechanical mixing according to the same formula. It should be noted that $2 \mathrm{phr}$ sulfur was also added into the two compounds for the following crosslinking. Finally, the pure SBR, GO/SBR and S-GO/SBR compounds were compression-molded and crosslinked at $160{ }^{\circ} \mathrm{C}$ and $15 \mathrm{MPa}$ to obtain rubber composites. The curing time of pure SBR, GO/SBR and S-GO/SBR composites determined by an oscillating disc rheometer (Model MR-C3, Beijing Ruida Yuchen Instrument Co., Ltd., China) were $3.9 \mathrm{~min}, 6.5 \mathrm{~min}$ and $8.3 \mathrm{~min}$, respectively.

\subsection{Characterization}

Transmission electron microscopy (TEM) and TEM energy dispersive X-ray spectroscopy (EDS) measurements were conducted on a G2 20 S-TWIN transmission electron microscope (FEI Corporation, USA) operated at a $300 \mathrm{kV}$ accelerating voltage. X-ray diffraction (XRD) measurements were carried out on a D/Max 2500 VB2+/PC diffractometer (Rigaku Corporation, Japan) with $\mathrm{Cu} \mathrm{K}$ radiation $(40 \mathrm{kV}$, $200 \mathrm{~mA}$ ) in the range of $5^{\circ}$ to $70^{\circ}$ with a scan rate of $5^{\circ} \mathrm{min}^{-1}$. Raman spectroscopy was carried out using a Renishaw inVia confocal microscope (Renishaw, England) with an excitation laser beam wavelength of $514 \mathrm{~nm}$. X-ray photoelectron spectroscopy (XPS) analysis was carried out on an ESCALAB 250 XPS system (Thermo Electron Corporation, USA) with an Al Ka X-ray source. A Rubber Processing Analyzer (RPA) (RPA 2000, Alpha Technologies Co, USA) was used to investigate the filler network at a frequency of $1 \mathrm{~Hz}$ at $60{ }^{\circ} \mathrm{C}$. Dynamic mechanical analysis (DMA) measurements were conducted on a VA3000 (01-dB Corporation, France) in the tension mode at a frequency of $10 \mathrm{~Hz}$ in the range of $-80^{\circ} \mathrm{C}$ to $80^{\circ} \mathrm{C}$ at a heating rate of $3^{\circ} \mathrm{C} \mathrm{min}{ }^{-1}$. Atomic force microscopy (AFM) measurements were performed on a MultiMode 8 microscope (Bruker, Germany) operated in the peak force quantitative nanomechanical (PF-QNM) mode with an excitation frequency of $2 \mathrm{kHz}$. Modulus maps according to Derjaguin-Muller-Toropov theoretical model (DMT) were generated by NanoScope Analysis software to characterize the thickness of interphase of GO/SBR composites and S$\mathrm{GO} / \mathrm{SBR}$ composites. A transverse line was drawn through the matrix area, interphase area and GO area to obtain the spatial gradient change of the modulus from the matrix to GO region. Then, the modulus ( $\mathrm{Pa}$ ) versus position (length) (nm) curve was obtained. The corresponding length of transition region on the curve represents the thickness of the interphase $[23,24]$. In order to accurately obtain the thickness of the interphase, twenty appropriate sheets were chosen for measurement. Differential scanning calorimeter (DSC) measurements were carried out on STARe System (Mettler-Toledo, LLC, Switzerland) in the range of $25^{\circ} \mathrm{C}-300^{\circ} \mathrm{C}$ with a heating rate of $10^{\circ} \mathrm{C} \mathrm{min}^{-1}$. Electron spin resonance (ESR) measurements were carried out on a Bruker ESP-500 instrument (Bruker Beijing Scientific Technologies Co. Ltd.). The power and frequency of the microwave radiation were $100 \mathrm{~mW}$ and $9.4 \mathrm{GHz}$, respectively. Fourier transform infrared (FTIR) measurements were carried on a Bruker Tensor 27 spectrometer with $\mathrm{KBr}$ thin pellets in the wavenumber range of $4000-400 \mathrm{~cm}^{-1}$. The Crosslinking density of the vulcanizates were characterized by nuclear magnetic resonance (NMR) spectroscopy (VTMR20-010V-1, Suzhou Niumag Corporation, China) at a frequency of $15 \mathrm{MHz}$, magnetic induction intensity of $0.5 \pm 0.05 \mathrm{~T}$ and temperature of $90{ }^{\circ} \mathrm{C}$. The bound rubber content in GO/SBR and S$\mathrm{GO} / \mathrm{SBR}$ compounds were measured based on the method reported by Leblanc [25]. Nitrogen permeability tests were carried out on a gas permeability-measuring apparatus at $40^{\circ} \mathrm{C}$ according to ISO 2782 . The sample sheet was approximately $1 \mathrm{~mm}$ in thickness and $8 \mathrm{~cm}$ in diameter. The pressure on one face of the sample was kept at $0.57 \mathrm{MPa}$, while on the other face was initially zero. The nitrogen permeability was calculated from the transmission rate of nitrogen determined by gas chromatography. The mechanical properties were determined using a CTM4104 tensile test machine (SANS, Shenzhen, China). The tensile and tear tests were carried out according to ISO 37: 2005 and ISO 34-1: 2004, respectively.

\section{Results and discussion}

\subsection{Morphology and structure of S-GO hybrids}

TEM was used to determine the presence of sulfur on the surface of GO nanosheets. Fig. 2 (a) shows that the large flakes of GO were transparent and had a large number of wrinkles on the surface, exhibiting the characteristics of a single layer of GO [26]. Fig. 2 (b) shows that some spherical particles with diameters of about $28 \mathrm{~nm}$ appeared on the surface of the GO and were proved to be sulfur particles by the TEM-EDS. Sulfur particles were formed from the reaction between $\mathrm{HCl}$ and $\mathrm{Na}_{2} \mathrm{~S}_{2} \mathrm{O}_{3}$. The sulfur generated tended to in situ deposit on the surface of GO due to the low activation energy involved with heterogeneous nucleation, rather than nucleating by itself to form large sulfur

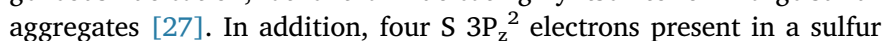
molecule had an interaction with antibonding conjugated $\pi^{*}$ states of the GO plane [28], resulting into the strong absorption of sulfur particles on the surface of GO.

Fig. 3 (a) shows the XRD patterns of sulfur, GO and S-GO hybrids. For sulfur, the curve shows two prominent peaks at 23.1 and $27.7^{\circ}$, corresponding to the (222) and (0 40) reflections of orthorhombic $\alpha$ sulfur $\mathrm{S}_{8}$ (JCPSD no. 08-0247). This crystalline structure of sulfur is the same as in commercial sulfur [29], indicating that the prepared sulfur was capable of being used as a crosslinking agent for rubber. For GO, 

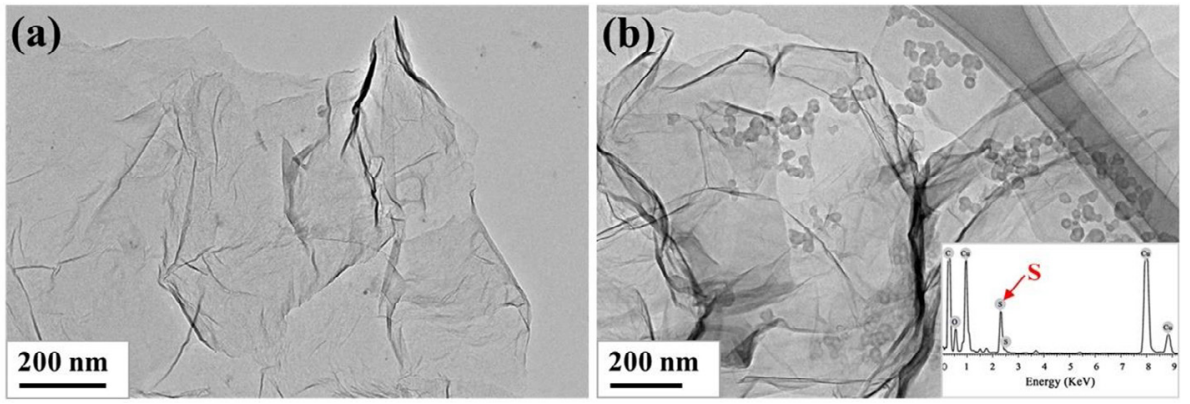

Fig. 2. TEM images of (a) GO and (b) S-GO hybrids. The plot inset in (b) is the TEM-EDS analysis of S-GO hybrids.

the curve shows characteristic of $\left(\begin{array}{lll}0 & 0 & 2\end{array}\right)$ diffraction at $12.6^{\circ}$. For S-GO hybrids, all the characteristic peaks of sulfur appeared in the plot. However, the peak at $12.6^{\circ}$ for GO disappeared, revealing the exfoliation state of the GO layers due to the in situ growth of sulfur particles between them.

Fig. 3 (b) shows the Raman spectra of sulfur, GO and S-GO hybrids. In the plot for sulfur, the characteristic peaks appeared at 153, 218 and $473 \mathrm{~cm}^{-1}$, attributed to the $A_{1}$ symmetry mode of the S-S bond in sulfur [30]. In the plots for GO and S-GO hybrids, the strong D-band and Gband appeared at $1351 \mathrm{~cm}^{-1}$ and $1596 \mathrm{~cm}^{-1}$, respectively. The intensity ratio of D-band and G-band was almost unchanged, demonstrating that the presence of sulfur on the surface didn't destroy the structure of GO. In addition, the characteristic peaks of sulfur appeared in the spectrum of S-GO, further indicating that sulfur is successfully deposited on the surface of the GO.

The XPS test was conducted to further confirm the composition of the surface chemical groups of GO and S-GO hybrids. In Fig. 4 (a), the XPS full spectrum shows that the peaks attributed to sulfur also appeared in the curve for S-GO hybrids, further confirming that the GO surface was deposited with sulfur particles. Fig. 4 (b) and (c) show that different oxygen-containing functional groups appeared on the surface of GO and S-GO hybrids. No significant changes in the content of oxygen-containing groups suggests that the introduction of sulfur did not influence the hydrophilicity of GO. The good water solubility of SGO hybrids was beneficial to the good dispersion of GO in the SBR matrix when the S-GO/SBR masterbatches were flocculated from the mixture solution composed of S-GO solution and SBR latex.

\subsection{Microstructure and properties of $S$-GO/SBR composites}

\subsubsection{Filler dispersion of $S-G O / S B R$ composite}

For ensuring the dispersion of GO and S-GO in SBR matrices, latex compounding and the ensuing co-coagulation were used in the preparation of the two composites. XRD was performed to evaluate the integral dispersion state of GO sheets in SBR composites. As shown in Fig. 5, the broad diffraction peaks around $20^{\circ}$ are attributed to the noncrystalline structure of SBR, and the diffraction peaks from $30^{\circ}$ to $70^{\circ}$ are assigned to $\mathrm{ZnO}$ particles in the composites [31]. No obvious characteristic peaks of GO or rGO aggregates appears in the patterns of GO/SBR and S-GO/SBR composites [32,33], suggesting that GO and SGO have a good integral dispersion state in the composites.

TEM was used to observe the localized dispersion of GO sheets in SBR composites. As shown in Fig. 6 (a), most GO sheets well dispersed as thin dark lines in GO/SBR composites. However, a few of GO aggregations were evident as thick dark lines in the SBR matrix, owing to the large difference in surface energy between GO and SBR [16]. GO layers tended to agglomerate with each other. This was caused by thermal driving force during the process of crosslinking at high temperature $[34,35]$. In contrast, Fig. 6 (b) shows that S-GO hybrids were uniformly dispersed throughout the viewing area without aggregation. This was because the sulfur on the surface of GO could melt during the crosslinking process at high temperature and spread on the surface of $\mathrm{GO}$, thus reducing the surface energy of GO and preventing GO agglomeration.

\subsubsection{The filler network and interfacial interactions in $S-G O / S B R$ composites}

The strain amplitude dependence of the storage modulus ( $\left.\mathrm{G}^{\prime}\right)$ of a rubber compound can be used to analyze the filler network. As shown in Fig. 7 (a), with an increase in strain, the G' of pure SBR, GO/SBR, S$\mathrm{GO} / \mathrm{SBR}$ compounds first appear to be at relatively constant levels and then decrease rapidly. Compared with pure SBR, the $\mathrm{G}^{\prime}$ of GO/SBR compounds was much higher, indicating a tight filler network composed of GO sheets was constructed in the rubber matrices. The filler network was beneficial in forming tortuous paths for gas penetration and improving the barrier properties of the composites. Moreover, S$\mathrm{GO} / \mathrm{SBR}$ compounds exhibited higher $\mathrm{G}^{\prime}$ values compared with $\mathrm{GO} / \mathrm{SBR}$ compounds at the same GO content. This improvement is mainly attributed to the strong interactions between GO and rubber chains. It is noted that this phenomenon is not same with weakened Payne effect of rubber composites containing silica aggregates after filler chemical modification $[36,37]$. The main reason is that strong interfacial
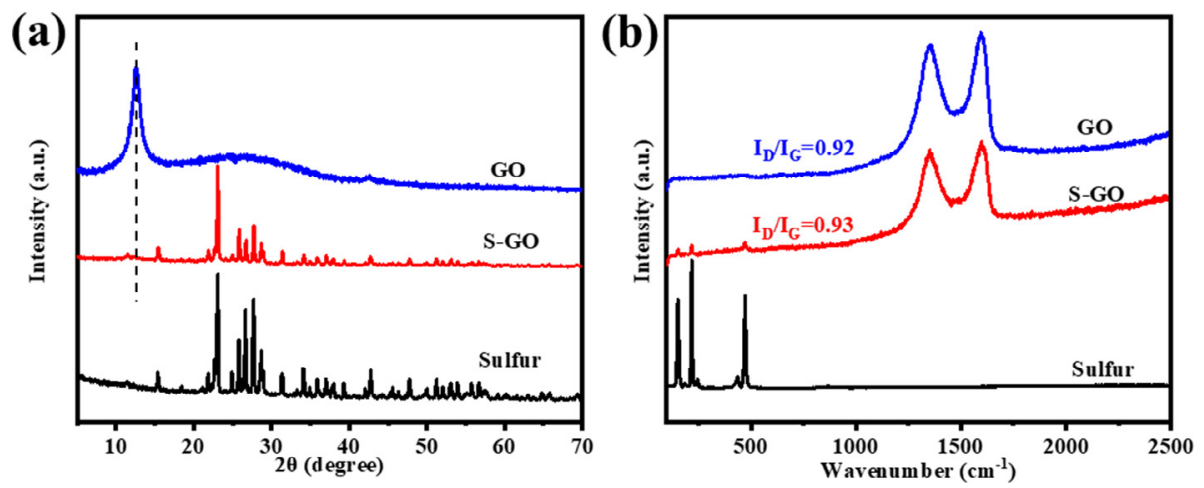

Fig. 3. (a) XRD patterns and (b) Raman spectra of sulfur, GO and S-GO hybrids. 

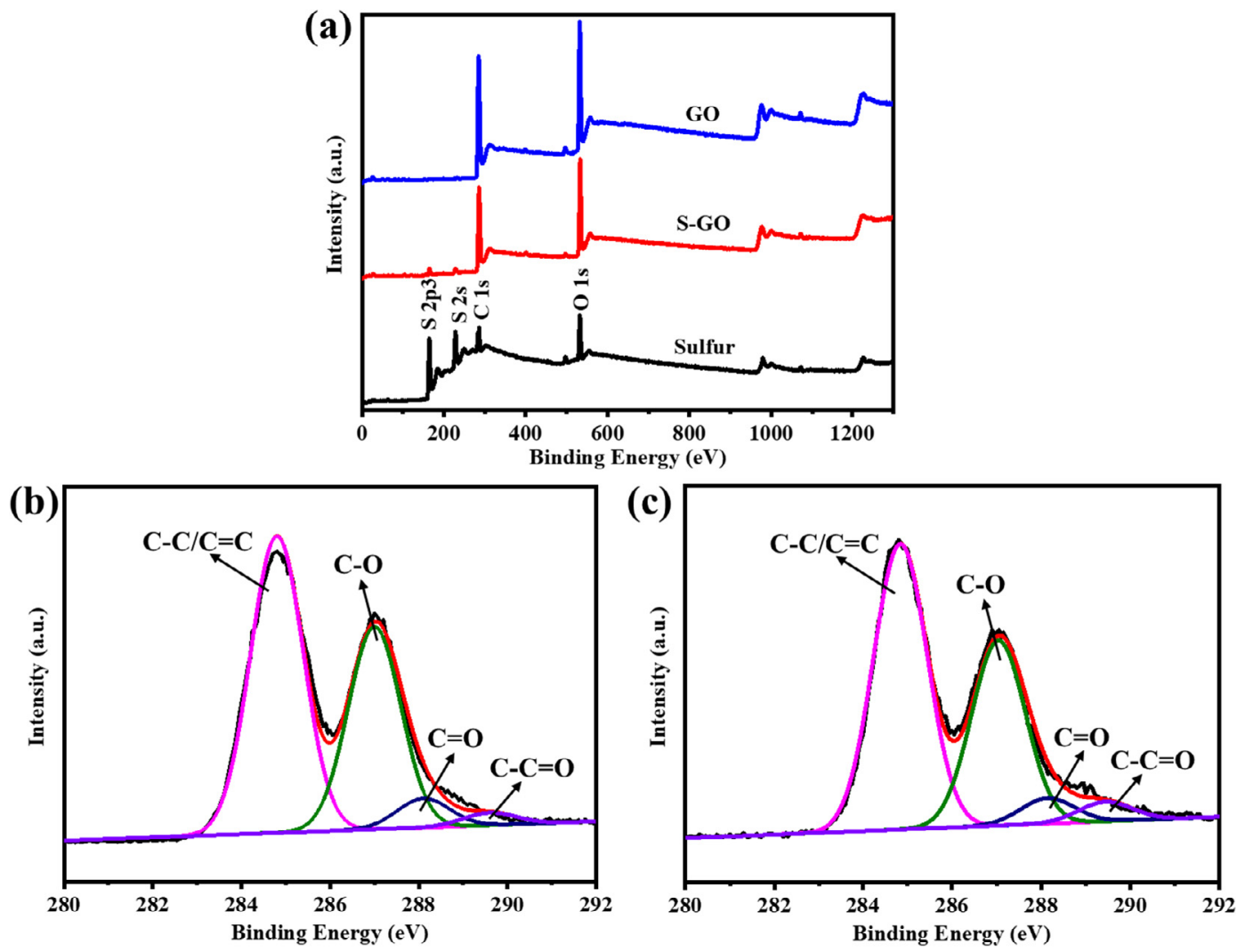

Fig. 4. (a) XPS survey spectra of sulfur, GO and S-GO hybrids; XPS spectra of C1s of (b) GO and (c) S-GO hybrids.

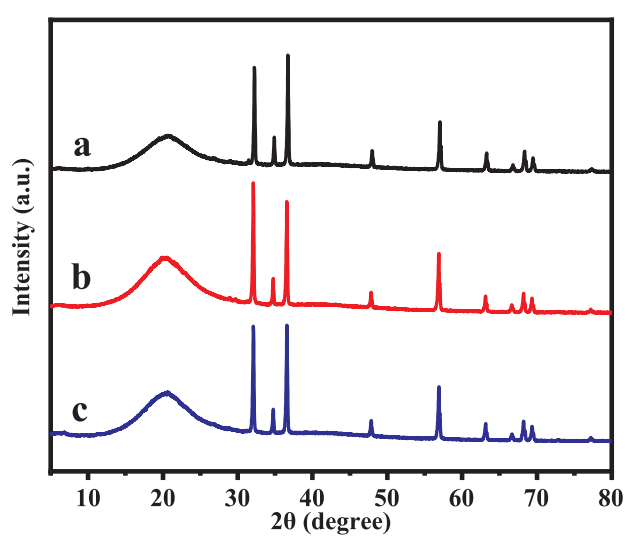

Fig. 5. XRD patterns of (a) SBR, (b) GO/SBR and (c) S-GO/SBR composites.

interactions in the silica filled rubber composites would greatly improve filler dispersion and decrease the filler network, thus leading to the weakened Payne effect. However, the fine dispersion of S-GO in SBR has been already obtained by the latex compounding. The strong interfacial interactions contributed to the tight filler networks which composed of S-GO sheets bridged by neighboring rubber molecules. The same phenomenon about Payne effect enhanced by strong interaction has been reported in the literatures $[38,39]$.

The interfacial interactions between GO and SBR molecules were studied by DMA. Fig. 7 (b) shows the loss factor $(\tan \delta$ ) as a function of temperature for all SBR composites. GO/SBR composites exhibited lower peak values of $\tan \delta$ than pure SBR composites, owing to the mobility of the SBR molecules being restricted by the filler network of the GO sheets. Furthermore, S-GO/SBR composites showed the lowest peak values of $\tan \delta$ for the three composites. This is attributed to stronger interfacial interactions between S-GO and SBR molecules in S$\mathrm{GO} / \mathrm{SBR}$ composites, leading to the further reduction of chain mobility [35]. The restrictions of SBR molecules by S-GO hybrids are beneficial to the improvement of gas barrier properties and mechanical properties.

The thickness of interphase between GO or S-GO and SBR molecules are evaluated quantitatively according to the gradient change in Young's modulus based on the PF-QNM technique. Fig. 8 (a) and (b) are
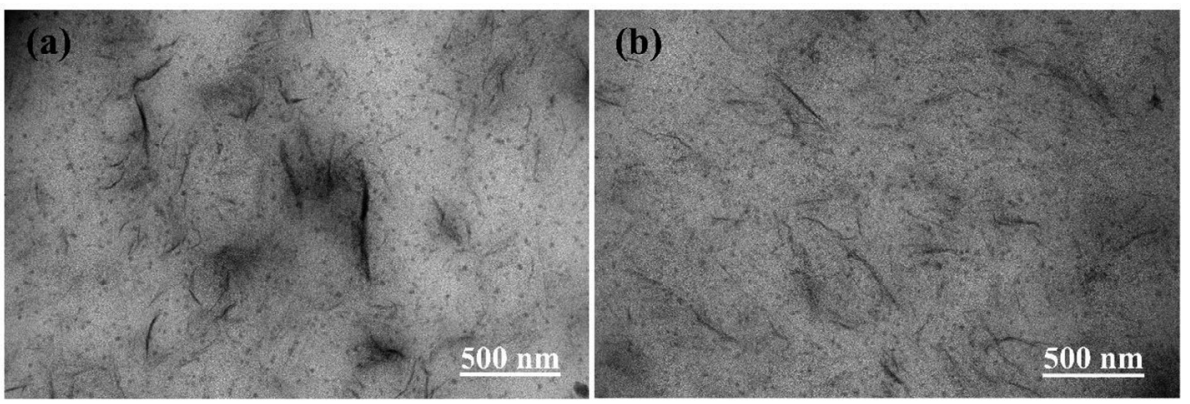

Fig. 6. TEM images of (a) GO/SBR and (b) S-GO/SBR composites. 

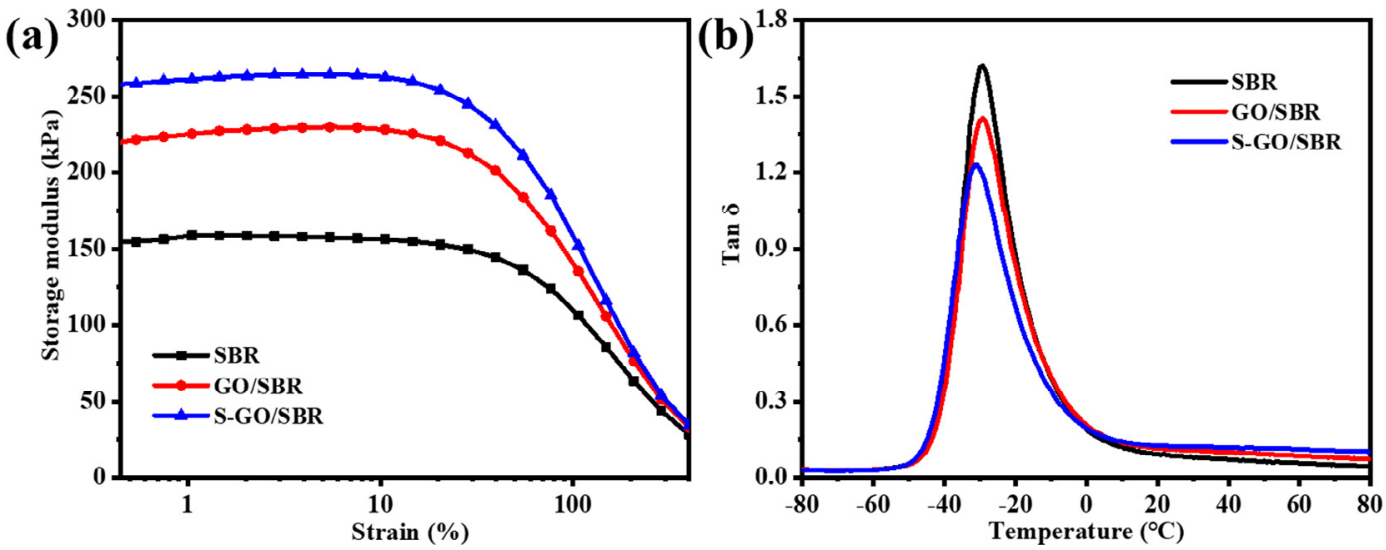

Fig. 7. (a) Storage modulus versus strain for SBR compounds; (b) $\tan \delta$ versus temperature for SBR composites.

the DMT Modulus maps of GO/SBR and S-GO/SBR composites, respectively. The modulus of composites versus length are presented in Fig. 8 (a') and (b'). The results showed that the average thicknesses of interphase in GO/SBR and S-GO/SBR composites was $62.7 \pm 10.5 \mathrm{~nm}$ and $86.1 \pm 13.3 \mathrm{~nm}$, respectively, indicating that the interfacial interactions between S-GO and SBR molecules were stronger than those between GO and SBR molecules. In addition, the thickness of the interphase between $\mathrm{GO}$ and the rubber matrix in this research is significantly higher than that observed for both spherical silica $(15.6 \pm 0.2 \mathrm{~nm})$ and one-dimensional carbon nanotubes
$(17.4 \pm 5.5 \mathrm{~nm})$ with rubber molecules as reported in previous literatures [23,37]. This is because GO is anisotropic and has a larger specific surface area, thus can absorb more rubber molecules which results in stronger interfacial interactions.

3.2.3. Mechanism of interfacial interaction between $S$-GO and $S B R$ molecules

The strong interaction between S-GO and SBR molecules was primarily formed during the crosslinking process at high temperature. To further understand the formation mechanism, DSC, EPR, and FTIR

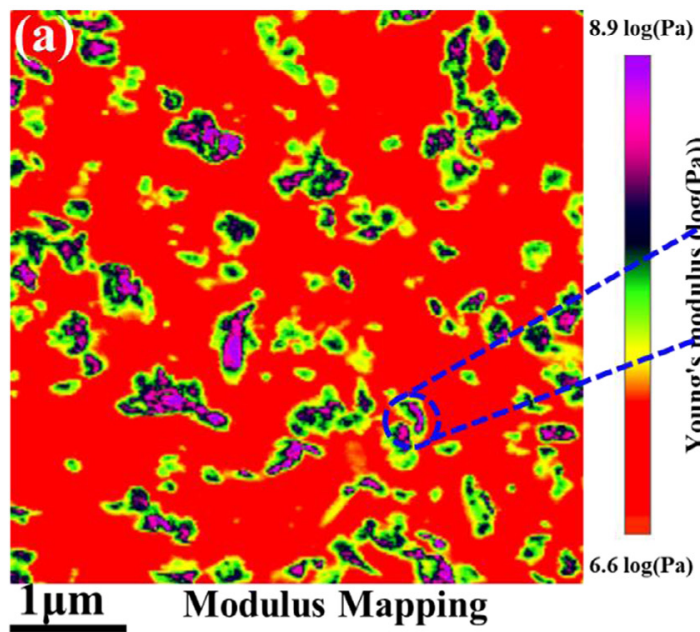

(a')
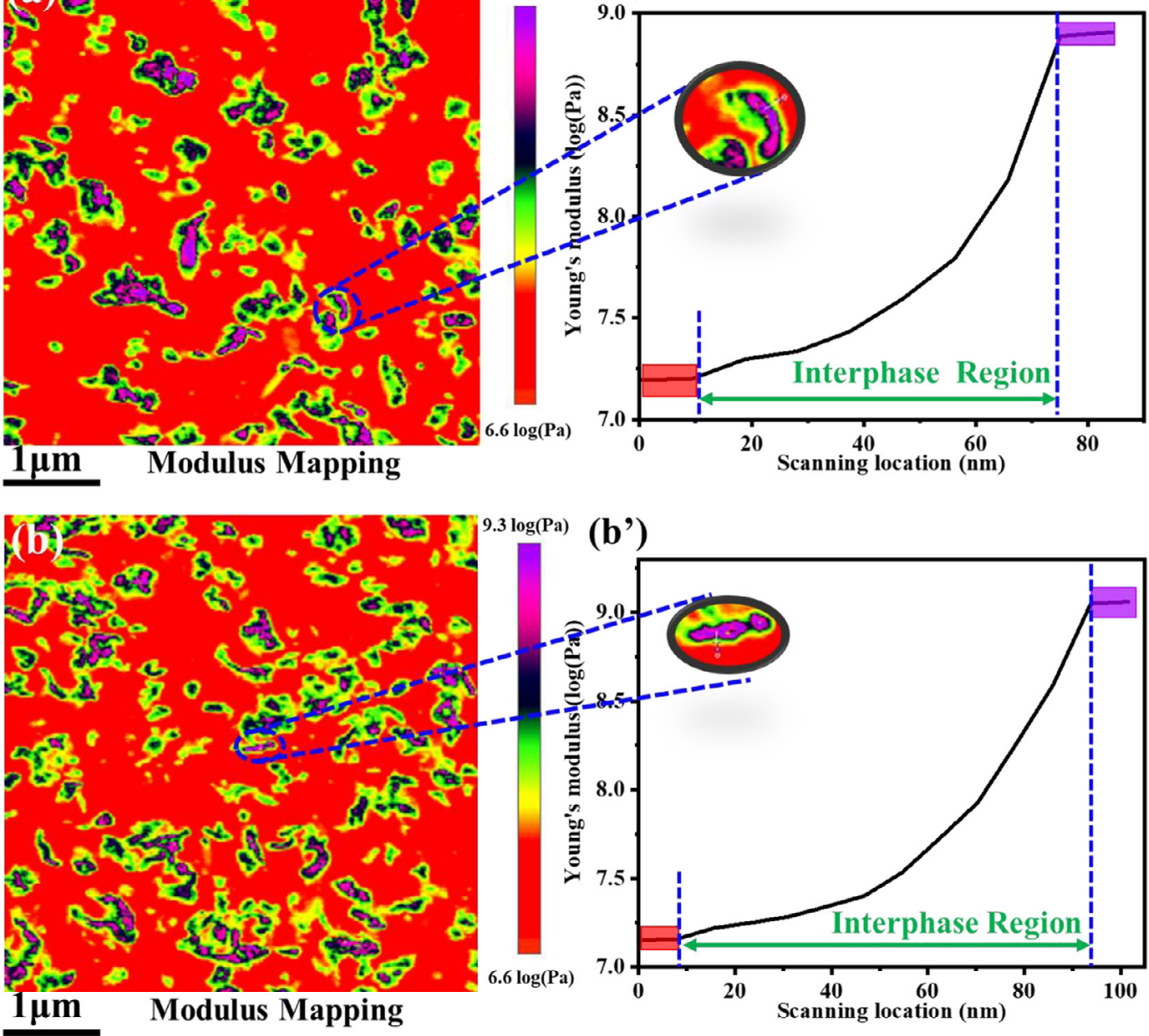

(b')

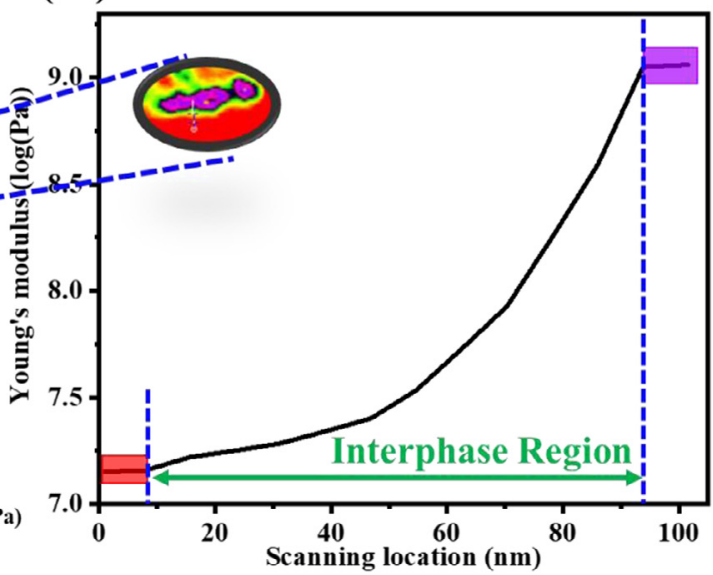

Fig. 8. Young's modulus maps of (a) GO/SBR and (b) S-GO/SBR composites and their corresponding modulus profiles (a') and (b') across the interphase, respectively. 

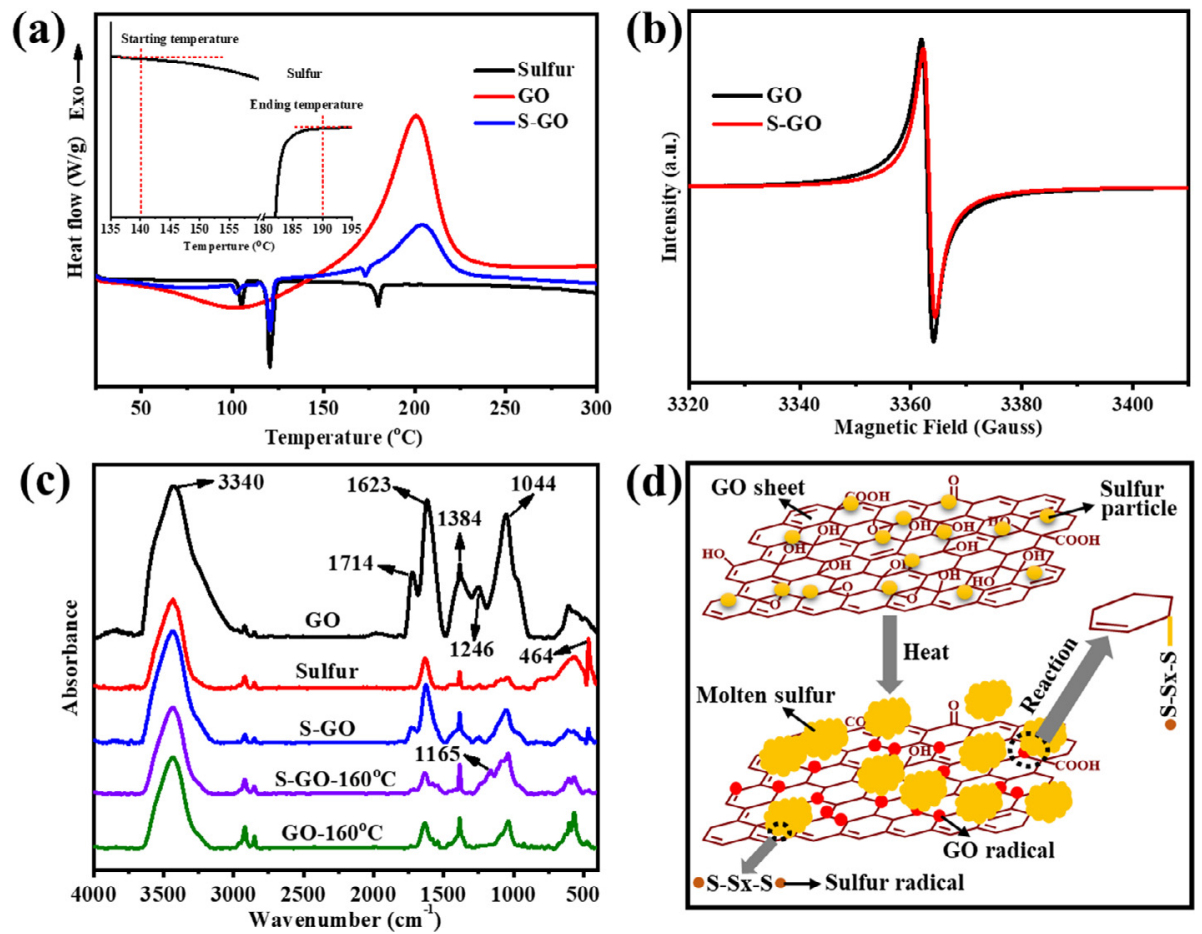

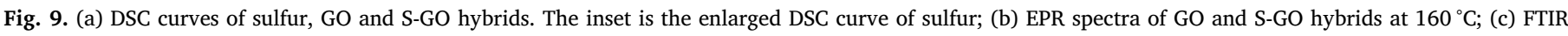
spectra of GO, sulfur, and S-GO hybrids before and after heat treatment at $160{ }^{\circ} \mathrm{C}$; (d) A diagrammatic representation of the reaction between GO and sulfur.

characterizations were carried out. Fig. 9 (a) shows the DSC curves of sulfur, GO and S-GO hybrids. For sulfur, the endothermic peak at $105{ }^{\circ} \mathrm{C}$ is attributed to the transformation of sulfur from orthorhombic $S\left(S_{\alpha}\right)$ to monoclinic $S\left(S_{\beta}\right)$, and the peak at $121{ }^{\circ} \mathrm{C}$ is attributed to the melting point of sulfur [40]. Therefore, during crosslinking process of S-GO/ SBR composites at $160^{\circ} \mathrm{C}$, sulfur would have melted immediately and infiltrated the surface of the GO sheets, hindering the aggregation of GO. The peak at $181^{\circ} \mathrm{C}$ is related to sulfur radicals generated from the homolytic fission of sulfur [40,41]. It can be known from the inset in Fig. 9 (a) the temperature of the homolytic fission of sulfur started at $140^{\circ} \mathrm{C}$ and ended at $190^{\circ} \mathrm{C}$, which is consistent with the research findings of Lian et al. [42]. Therefore, the sulfur radicals would be effective at the crosslinking temperature of $160{ }^{\circ} \mathrm{C}$. For GO, an endothermic peak around $100^{\circ} \mathrm{C}$ is attributed to the volatilization of absorbed water. An obvious exothermic wide peak starting from $142{ }^{\circ} \mathrm{C}$ to $246{ }^{\circ} \mathrm{C}$ is attributed to the partially thermal reduction of the GO. For S$\mathrm{GO}$ hybrids, the temperature related to the generation of sulfur radicals was shifted from $181^{\circ} \mathrm{C}$ to $173^{\circ} \mathrm{C}$. It is speculated that the heat released by the reduction of $\mathrm{GO}$ would have promoted the ring-opening reaction of sulfur adsorbed on GO surface.

Fig. 9 (b) shows the ESR spectra of GO and S-GO hybrids. Both the curves of GO and S-GO hybrids have sharp and intensive derivative peaks, indicating that free radicals of GO were generated by the cleavage of oxygenic groups (such as hydroxy and epoxy group) on GO planes when GO was partially thermally reduced during the crosslinking process at high temperature $[43,44]$. In order to verify the reaction between sulfur radicals and GO radicals at high temperature, the GO and S-GO hybrids, before and after the heat treatment at $160^{\circ} \mathrm{C}$, were characterized by FTIR and the results are shown in Fig. 9 (c).

In Fig. 9 (c), the peaks at 3340, 1714, 1623, 1384, 1246 and $1044 \mathrm{~cm}^{-1}$ for $\mathrm{GO}$ are assigned to the stretching vibration of $\mathrm{O}-\mathrm{H}, \mathrm{C}=$ $\mathrm{O}, \mathrm{C}=\mathrm{C}, \mathrm{C}-\mathrm{OH}, \mathrm{C}-\mathrm{O}-\mathrm{C}$ and $\mathrm{C}-\mathrm{O}$ group, respectively. For S-GO hybrids, the curve shows a new absorption peak at $464 \mathrm{~cm}^{-1}$, attributed to the stretching vibration of the S-S in the sulfur molecule. After heat treatment at $160{ }^{\circ} \mathrm{C}$, S-GO hybrids showed a new absorption peak at $1165 \mathrm{~cm}^{-1}$ assigned to the stretching vibration of the C-S bond on the benzene ring [45], which was not shown in the curve of heat-treated GO. This further confirmed covalent linkages between GO and sulfur were formed and the schematic of the reaction between GO and sulfur is shown in Fig. 9 (d).

Combining the above results, it can be concluded that the strong interface between S-GO and SBR molecules mainly originated from the reaction of GO radicals and sulfur radicals during the process of crosslinking at high temperature.

\subsubsection{Bound rubber content and crosslinking density of $S-G O / S B R$ composites}

The bound rubber content and crosslinking density of SBR composites are shown in Table 1. Bound rubber is the amount of rubber that is bound to the filler before crosslinking, and mainly generated from the interfacial interaction between fillers and rubber molecules. The bound rubber content of the S-GO/SBR composites is higher than that of the $\mathrm{GO} / \mathrm{SBR}$ composites, owing to the strong interfacial interactions between S-GO sheets and their neighboring rubber molecules, which was also confirmed by RPA tests in Fig. 7(a). The crosslinking density of $\mathrm{GO} / \mathrm{SBR}$ composites is higher than that of pure SBR, owing to the crosslinking network being enhanced by physical absorption of SBR molecules by GO sheets alongside the normal sulfur crosslinking of the network. Compared with GO/SBR composites, the crosslinking density of S-GO/SBR composites was slightly improved. The main reasons are as follows: (1) the sulfur particles in S-GO are much smaller and more uniform than sulfur aggregates, thus resulting into high contact opportunity between sulfur and SBR molecules and efficient crosslinking network in S-GO/SBR composites. (2) The covalent interfacial

Table 1

Bound rubber content and crosslinking density of SBR composites.

\begin{tabular}{llll}
\hline Samples & SBR & GO/SBR & \multicolumn{1}{l}{ S-GO/SBR } \\
\hline $\begin{array}{lll}\text { Bound rubber content }(\%) \\
\text { Crosslinking density } \\
\quad\left(\times 10^{-4} \mathrm{~mol} / \mathrm{ml}\right)\end{array}$ & - & $15.87 \pm 0.32$ & $19.93 \pm 0.46$ \\
& & $3.720 \pm 0.055$ & $3.934 \pm 0.041$ \\
& & &
\end{tabular}




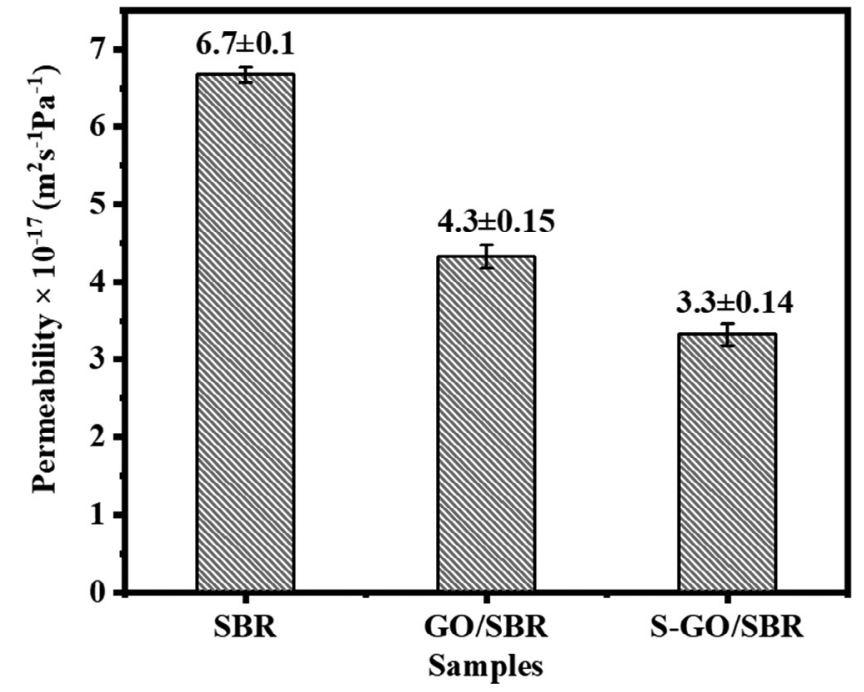

Fig. 10. Permeability of the pure SBR, GO/SBR and S-GO/SBR composites.

interaction was formed between GO and SBR molecules in S-GO/SBR composites after crosslinking process, further contributing to the crosslinking density of the S-GO/SBR composites. High crosslinking density of the S-GO/SBR composite is beneficial in reducing the free volume between SBR molecules and improving the gas barrier performance [46].

\subsubsection{Gas barrier properties of $S$-GO/SBR composites}

Figs. 10 and 11 shows the gas $\left(\mathrm{N}_{2}\right)$ permeability coefficients and schematic of the gas molecule diffusion in different composites, respectively. GO/SBR composites exhibited a much lower permeability when compared with pure SBR owing to the formation of complex filler network comprising GO sheets. However, only a few of GO had the opportunity to contact and react with sulfur in GO/SBR composites, resulting in a low degree of interface interactions between sulfur and GO (see Fig. 11 (a)). After the introduction of S-GO hybrids into SBR composites, the gas permeability coefficient of the S-GO/SBR composites further decreased by $50.7 \%$ and $23.3 \%$ when compared to those of pure SBR and GO/SBR composites. This is primarily attributed to the great reduction in free volumes originated from the strong interfacial interactions between S-GO and SBR molecules. In S-GO/SBR composites, GO and sulfur could react easily and form strong chemical interfaces due to the sufficient contact between GO and sulfur. The complex filler networks and strong interfacial interactions greatly decreased the free volumes between SBR molecules and prolonged the pathways and diffusion times of nitrogen molecules in SBR matrices

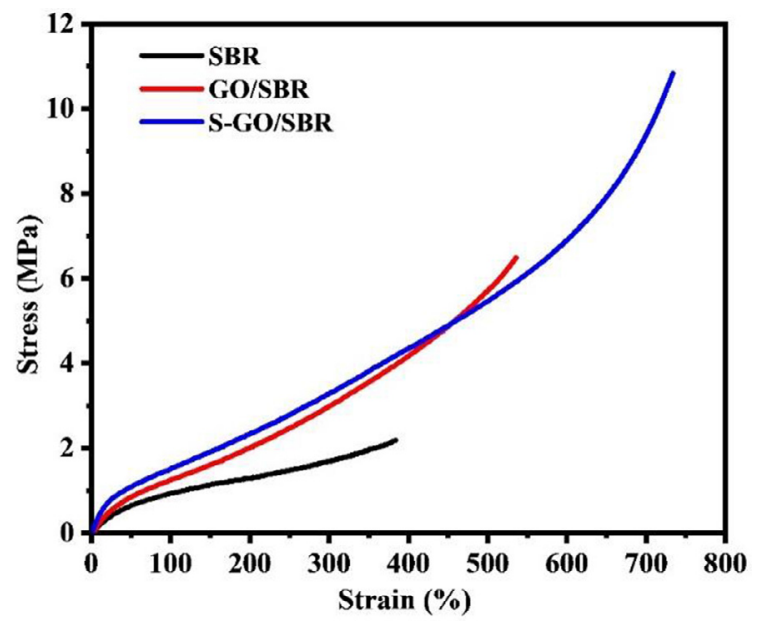

Fig. 12. Strain-Stress curves of SBR composites.

(see Fig. 11(b)), thus resulting in high gas barrier properties.

\subsubsection{Mechanical properties of $S$-GO/SBR composites}

The stress-strain curves of the SBR, GO/SBR and S-GO/SBR composites are displayed in Fig. 12 and the mechanical properties are summarized in Table 2. After the introduction of GO and S-GO into SBR, the tensile strength, tear strength, elongation at break, modulus at $100 \%$ and $300 \%$ strain of the composites are all dramatically improved by comparison with pure SBR composites. Moreover, S-GO/SBR composites exhibited higher tensile and tear strength than GO/SBR composites, owing to the strong interfacial interactions between S-GO and SBR molecules which were confirmed by the FTTR, ESR, and DSC characterizations (Fig. 9). The strong interactions facilitated an efficient stress transfer from the SBR matrix to the large GO sheets. When the GO content was $3 \mathrm{phr}$, the tensile strength and tear strength of the S-GO/ SBR composites increased by $66.2 \%$ and $26.6 \%$, respectively, compared with the GO/SBR composites.

\section{Conclusions}

In this research, sulfur particles were synthesized in situ on the surface of GO nanosheets to obtain S-GO hybrids. Then S-GO hybrids were compounded with SBR by latex compounding to prepare S-GO/ SBR composites. During the crosslinking process at high temperature, the sulfur on the surface of GO not only crosslinked the rubber chains, but also prevented the agglomeration of GO sheets by the melting and spreading of sulfur on the surface of the GO. More importantly, sulfur reacted with the GO and bridged the GO to the SBR molecules, thereby

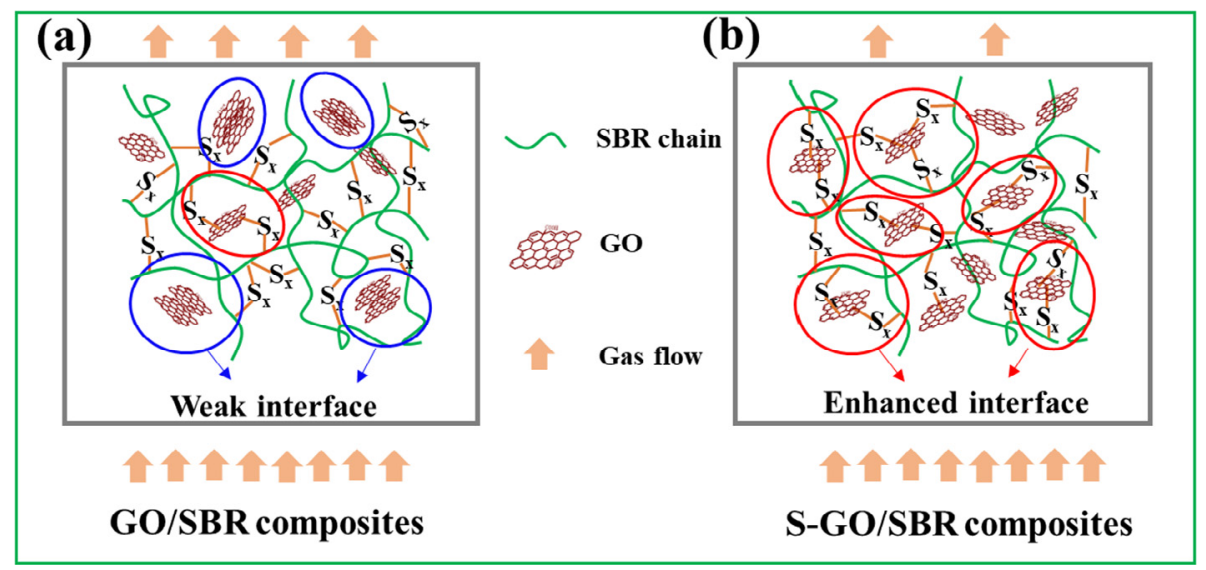

Fig. 11. Schematic of the gas molecule diffusion in GO/SBR and S-GO/SBR composites. 
Table 2

Mechanical properties of SBR composites

\begin{tabular}{llll}
\hline Sample & SBR & GO/SBR & S-GO/SBR \\
\hline Tensile strength (MPa) & $2.2 \pm 0.2$ & $6.5 \pm 0.5$ & $10.8 \pm 0.9$ \\
Tear strength (kN/m) & $10.3 \pm 1.2$ & $21.4 \pm 2.3$ & $27.1 \pm 2.5$ \\
Elongation at break (\%) & $384 \pm 14$ & $536 \pm 17$ & $733 \pm 24$ \\
Modulus at 100\% strain (MPa) & $0.9 \pm 0.1$ & $1.2 \pm 0.1$ & $1.5 \pm 0.1$ \\
Modulus at 300\% strain (MPa) & $1.7 \pm 0.1$ & $3.0 \pm 0.1$ & $3.3 \pm 0.1$ \\
Shore A hardness & $42 \pm 1$ & $47 \pm 1$ & $50 \pm 1$ \\
& & &
\end{tabular}

constructing strong interfaces and filler networks in SBR matrices. The interfacial thicknesses and crosslinking density of S-GO/SBR composites were higher than those of GO/SBR composites. The complex filler networks and strong interfacial interactions in the S-GO/SBR composites resulted in increases by $66.2 \%$ in tensile strength and decreases by $23.3 \%$ in gas permeability coefficients when compared with those in the GO/SBR composites. In conclusion, the current work provides a facile and effective method to design multifunctional rubber crosslinking agent and prepare rubber composites with high performance.

\section{Acknowledgments}

We gratefully acknowledge financial support from the National Basic Research Program of China (2015CB654700(2015CB654705)), the National Natural Science Foundation of China (51573007) and the National Key R\&D Program of China (2017YFE0126800).

\section{Appendix A. Supplementary data}

Supplementary data to this article can be found online at https:// doi.org/10.1016/j.cej.2019.123100.

\section{References}

[1] B. Guo, Z. Tang, L. Zhang, Transport performance in novel elastomer nanocomposites: Mechanism, design and control, Prog. Polym. Sci. 61 (2016) 29-66.

[2] A.P. Meera, T.P. Selvin, S. Thomas, Effect of organoclay on the gas barrier properties of natural rubber nanocomposites, Polym. Compos. 33 (2012) 524-531.

[3] C. Zha, W. Wang, Y. Lu, L. Zhang, Constructing covalent interface in rubber/clay nanocomposite by combining structural modification and Inter lamellar silylation of montmorillonite, ACS Appl. Mater. Interfaces 6 (2014) 18769-18779.

[4] L. Mao, H.-Q. Wu, Y.-J. Liu, J. Yao, Y.-K. Bai, Enhanced mechanical and gas barrier properties of poly( $\varepsilon$-caprolactone) nanocomposites filled with tannic acid-Fe(III) functionalized high aspect ratio layered double hydroxides, Mater. Chem. Phys. 211 (2018) 501-509.

[5] L.M. Wang, Y.B. Dou, J.J. Wang, J.B. Han, L. Liu, M. Wei, Layer-by-layer assembly of layered double hydroxide/rubber multilayer films with excellent gas barrier property, Compos. A Appl. Sci. Manuf. 102 (2017) 314-321.

[6] N. Yan, G. Buonocore, M. Lavorgna, S. Kaciulis, S.K. Balijepalli, Y. Zhan, H. Xia, L. Ambrosio, The role of reduced graphene oxide on chemical, mechanical and barrier properties of natural rubber composites, Compos. Sci. Technol. 102 (2014) 74-81.

[7] S.H. Song, J.M. Kim, K.H. Park, D.J. Lee, O.S. Kwon, J. Kim, H. Yoon, X. Chen, High performance graphene embedded rubber composites, RSC Adv. 5 (2015) 81707-81712.

[8] G. Scherillo, M. Lavorgna, G.G. Buonocore, Y.H. Zhan, H.S. Xia, G. Mensitieri, L. Ambrosio, Tailoring assembly of reduced graphene oxide nanosheets to control gas barrier properties of natural rubber nanocomposites, ACS Appl. Mater. Interfaces 6 (2014) 2230-2234.

[9] C. Wolf, H. Angellier-Coussy, N. Gontard, F. Doghieri, V. Guillard, How the shape of fillers affects the barrier properties of polymer/non-porous particles nanocomposites: A review, J. Membr. Sci. 556 (2018) 393-418.

[10] N. Selvakumar, A. Biswas, S.B. Krupanidhi, H.C. Barshilia, Enhanced optical absorption of graphene-based heat mirror with tunable spectral selectivity, Sol. Energy Mater. Sol. Cells 186 (2018) 149-153.

[11] L. Liu, K. Zheng, Y. Yan, Z. Cai, S. Lin, X. Hu, Graphene aerogels enhanced phase change materials prepared by one-pot method with high thermal conductivity and large latent energy storage, Sol. Energy Mater. Sol. Cells 185 (2018) 487-493.

[12] E. Šest, G. Dražič, B. Genorio, I. Jerman, Graphene nanoplatelets as an anticorrosion additive for solar absorber coatings, Sol. Energy Mater. Sol. Cells 176 (2018) 19-29.

[13] H. Kang, K. Zuo, Z. Wang, L. Zhang, L. Liu, B. Guo, Using a green method to develop graphene oxide/elastomers nanocomposites with combination of high barrier and mechanical performance, Compos. Sci. Technol. 92 (2014) 1-8.

[14] Z. Tang, X. Wu, B. Guo, L. Zhang, D. Jia, Preparation of butadiene-styrene-vinyl pyridine rubber-graphene oxide hybrids through co-coagulation process and in situ interface tailoring, J. Mater. Chem. 22 (2012) 7492.

[15] J. Wei, S. Jacob, J. Qiu, Graphene oxide-integrated high-temperature durable fluoroelastomer for petroleum oil sealing, Compos. Sci. Technol. 92 (2014) 126-133.

[16] Z. Tang, L. Zhang, W. Feng, B. Guo, F. Liu, D. Jia, Rational design of graphene surface chemistry for high-performance rubber/graphene composites, Macromolecules 47 (2014) 8663-8673.

[17] Y. Luo, Y. Wu, K. Luo, F. Cai, T. Zhai, S. Wu, Structures and properties of alkanethiol-modified graphene oxide/solution-polymerized styrene butadiene rubber composites: Click chemistry and molecular dynamics simulation, Compos. Sci. Technol. 161 (2018) 32-38.

[18] X. Yang, Y. Zhang, Y. Xu, S. Gao, S. Guo, Effect of octadecylamine modified graphene on thermal stability, mechanical properties and gas barrier properties of brominated butyl rubber, Macromol. Res. 25 (2017) 270-275.

[19] J. Wu, G. Huang, H. Li, S. Wu, Y. Liu, J. Zheng, Enhanced mechanical and gas barrier properties of rubber nanocomposites with surface functionalized graphene oxide at low content, Polymer 54 (2013) 1930-1937.

[20] S. Kaciulis, A. Mezzi, S.K. Balijepalli, M. Lavorgna, H.S. Xia, Electron spectroscopy of rubber and resin-based composites containing 2D carbon, Thin Solid Films 581 (2015) 80-85.

[21] Z. Yang, J. Liu, R. Liao, G. Yang, X. Wu, Z. Tang, B. Guo, L. Zhang, Y. Ma, Q. Nie, F. Wang, Rational design of covalent interfaces for graphene/elastomer nanocomposites, Compos. Sci. Technol. 132 (2016) 68-75.

[22] W.S. Hummers, R.E. Offeman, Preparation of graphitic oxide, J. Am. Chem. Soc. 80 (1958) 1339.

[23] C. Tian, G. Chu, Y. Feng, Y. Lu, C. Miao, N. Ning, L. Zhang, M. Tian, Quantitatively identify and understand the interphase of $\mathrm{SiO} 2 /$ rubber nanocomposites by using nanomechanical mapping technique of AFM, Compos. Sci. Technol. 170 (2019) 1-6.

[24] Y. Gu, M. Li, J. Wang, Z. Zhang, Characterization of the interphase in carbon fiber/ polymer composites using a nanoscale dynamic mechanical imaging technique, Carbon 48 (2010) 3229-3235.

[25] J. Leblanc, P. Hardy, Evolution of bound rubber during the storage of uncured compounds, Kautschuk und Gummi, Kunststoffe 44 (1991) 1119-1124.

[26] M. Kim, C. Lee, Y.D. Seo, S. Cho, J. Kim, G. Lee, Y.K. Kim, J. Jang, Fabrication of various conducting polymers Using graphene oxide as a chemical oxidant, Chem. Mater. 27 (2015) 6238-6248.

[27] Y.S. Su, Y. Fu, A. Manthiram, Self-weaving sulfur-carbon composite cathodes for high rate lithium-sulfur batteries, PCCP 14 (2012) 14495-14499.

[28] T. Lin, Y. Tang, Y. Wang, H. Bi, Z. Liu, F. Huang, X. Xie, M. Jiang, Scotch-tape-like exfoliation of graphite assisted with elemental sulfur and graphene-sulfur composites for high-performance lithium-sulfur batteries, Energy Environ. Sci. 6 (2013) 1283.

[29] S. Shukla, A. Ghosh, P.K. Roy, S. Mitra, B. Lochab, Cardanol benzoxazines - A sustainable linker for elemental sulphur based copolymers via inverse vulcanisation, Polymer 99 (2016) 349-357.

[30] A.T. Ward, Raman spectroscopy of sulfur, sulfur-selenium, and sulfur-arsenic mixtures, J. Phys. Chem. 72 (1968) 4133-4139.

[31] Z. Xu, L. Zheng, S. Wen, L. Liu, Graphene oxide-supported zinc oxide nanoparticles for chloroprene rubber with improved crosslinking network and mechanical properties, Compos. A Appl. Sci. Manuf. 124 (2019) 105492.

[32] B. Yin, X. Zhang, X. Zhang, J. Wang, Y. Wen, H. Jia, Q. Ji, L. Ding, Ionic liquid functionalized graphene oxide for enhancement of styrene-butadiene rubber nanocomposites, Polym. Adv. Technol. 28 (2017) 293-302.

[33] Z. Yang, H. Liu, S. Wu, Z. Tang, B. Guo, L. Zhang, A green method for preparing conductive elastomer composites with interconnected graphene network via Pickering emulsion templating, Chem. Eng. J. 342 (2018) 112-119.

[34] D. Wang, S. Chen, L. Chen, B. Chen, F. Ren, C. Zhu, J. Feng, Investigation and improvement of the scorch behavior of silica-filled solution styrene-butadiene rubber compound, J. Appl. Polym. Sci. 136 (2019) 47918.

[35] X. Liu, W. Kuang, B. Guo, Preparation of rubber/graphene oxide composites with in situ interfacial design, Polymer 56 (2015) 553-562.

[36] J. Ramier, C. Gauthier, L. Chazeau, L. Stelandre, L. Guy, Payne effect in silica-filled styrene-butadiene rubber: Influence of surface treatment, J. Polym. Sci., Part B: Polym. Phys. 45 (2007) 286-298.

[37] J. Zheng, D. Han, S. Zhao, X. Ye, Y. Wang, Y. Wu, D. Dong, J. Liu, X. Wu, L. Zhang, Constructing a multiple covalent interface and isolating a dispersed structure in silica/rubber nanocomposites with excellent dynamic Performance, ACS Appl. Mater. Interfaces 10 (2018) 19922-19931.

[38] Y. Chen, Z. Li, S. Wen, Q. Yang, L. Zhang, C. Zhong, L. Liu, Molecular simulation study of role of polymer-particle interactions in the strain-dependent viscoelasticity of elastomers (Payne effect), J. Chem. Phys. 141 (2014) 104901.

[39] C. Sun, Z. Du, S. Nagarajan, H. Zhao, S. Wen, S. Zhao, P. Zhang, L. Zhang, Impact of uniaxial tensile fatigue on the evolution of microscopic and mesoscopic structure of carbon black filled natural rubber, R. Soc. Open Sci. 6 (2019) 181883.

[40] B.K. Bordoloi, E.M. Pearce, Plastic sulfur stabilization by copolymerization of sulfur with dicyclopentadiene, Adv. Chem. 165 (1978) 31-53.

[41] W.J. Chung, J.J. Griebel, E.T. Kim, H. Yoon, A.G. Simmonds, H.J. Ji, P.T. Dirlam, R.S. Glass, J.J. Wie, N.A. Nguyen, B.W. Guralnick, J. Park, A. Somogyi, P. Theato, M.E. Mackay, Y.E. Sung, K. Char, J. Pyun, The use of elemental sulfur as an alternative feedstock for polymeric materials, Nat. Chem. 5 (2013) 518-524.

[42] Q. Lian, Y. Li, K. Li, J. Cheng, J. Zhang, Insights into the vulcanization mechanism through a simple and facile approach to the sulfur cleavage behavior, Macromolecules 50 (2017) 803-810.

[43] R. Feng, W. Zhou, G. Guan, C. Li, D. Zhang, Y. Xiao, L. Zheng, W. Zhu, Surface 
decoration of graphene by grafting polymerization using graphene oxide as the initiator, J. Mater. Chem. 22 (2012) 3982.

[44] X.-L. Hou, J.-L. Li, S.C. Drew, B. Tang, L. Sun, X.-G. Wang, Tuning radical species in graphene oxide in aqueous solution by photoirradiation, J. Phys. Chem. C 117 (2013) 6788-6793.

[45] Y.G. Yan, M.J. Xie, Y.R. Chen, W.U. Qi Xian, Y.U. Zi Li, Study on the synthsis and structure of polyphenylene sulfide, J. Sichuan Univ. (Natural Science Edition) 36 (1999) 535-540.

[46] S.J. He, Y.Q. Wang, J. Lin, L.Q. Zhang, Improving the gas barrier property of SBR/ clay nanocomposite through In situ sulfur modification during curing process, Appl. Mech. Mater. 108 (2011) 48-51. 